Oikos 117: 1057-1063, 2008

doi: $10.1111 / j .2008 .0030-1299.16251 . x$,

(C) 2008 The Authors. Journal compilation (C) 2008 Oikos

Subject Editor: Katharine Suding. Accepted 19 February 2008

\title{
The interacting effects of herbivore exclosures and seed addition in a wet meadow
}

\author{
L. H. Fraser and E. B. Madson
}

L. H. Fraser (lfraser@tru.ca) and E. B. Madson, Dept of Biology, Univ. of Akron, Akron, OH 44325-3908, USA. LHF also at: Dept of Natural Resource Sciences, Thompson Rivers Univ., Kamloops, British Columbia, Canada, V2C 5 N3.

\begin{abstract}
Seed limitation may prevent successful restoration of native plant communities. Seed addition is a common restoration practice but the role of small mammals in affecting seedling recruitment is not well understood. The purpose of this investigation was to test the relative effect of seed introduction in combination with small mammal and bird exclosures in an Ohio wet meadow. We ask whether the ambient population of Microtus pennsylvanicus (1) alters species composition (e.g. forb/grass/sedge, invasive, non-native); (2) influences plant diversity; and (3) reduces the effect of increasing local plant richness through seed introductions. We established a $2 \times 2$ factorial design including a seed addition treatment $(0$ and 20 seed species added) and an exclosure treatment (open and fenced to exclude all mammalian and bird herbivores and granivores). Seeds from twenty native species were selected to represent a broad range of plant life forms typically found in temperate eastern North American wet meadow communities. All species were obligate or facultative wetland species with forbs, grasses and sedges represented. We found that forb species increased inside exclosures, especially in the seed addition treatment. We also found that relative biomass of invasive species was reduced in exclosures and with seed addition. Species richness increased with seed addition; however, exclosures significantly increased species richness and diversity, particularly of those species that were experimentally introduced by seed. Our results support the seed limitation hypotheses. It is also evident that seed and seedling predation are important factors that can control wet meadow community composition and diversity.
\end{abstract}

The factors that control species diversity and community composition provide the ecological template for the restoration, management and conservation of ecosystems (Noss and Cooperrider 1994, Grime 2001). One factor that can strongly influence species composition and plant diversity is herbivory (Crawley 1983, Huntly 1991). Large ungulates, for example, can have a strong effect on grassland abundance, composition and diversity (McNaughton et al. 1991, Milchunas and Laurenroth 1993, Knapp et al. 1999). Small mammals have also been shown to affect grassland vegetation but their influence is perhaps not as well appreciated (Batzli and Pitelka 1970, Hulme 1996, Keesing 2000, Howe et al. 2002, 2006, Howe and Lane 2004, MacDougall and Wilson 2007). While much attention has been directed towards understanding cyclic oscillations in vole and lemming populations in Europe and North America (Krebs et al. 2002, Huitu et al. 2003, Oli 2003), much less study has been done on how these small mammals affect vegetation. Small mammal herbivory has important consequences in North American grasslands, where native grazing ungulates are essentially non-existent (Noss et al. 1995). In many of these relict grasslands, small mammals may be the dominant herbivore; and yet, it is not well known how these herbivores affect grassland communities. Howe et al. (2006) illustrates the significant and distinctive effect meadow voles can have on grassland vegetation - within six years, meadow voles affected a change in a plant community such that it was dominated by species not consumed by the meadow vole. Small mammals can also influence grassland vegetation through granivory (Edwards and Crawley 1999, Howe and Brown 2000, 2001).

In restoration, addition of seeds is an expedient process of introducing desirable species when compared to natural colonization by the seed bank and seed rain (Pywell et al. 2002, Sheley and Half 2006). The purpose of seed addition is: (1) introduction, re-introduction and increase in numbers of native species (Carpinelli et al. 2004); (2) increasing species diversity to prevent non-native invasion from occurring (Bakker et al. 2003, Sheley and Half 2006); (3) preventing seedling limitation (Seabloom et al. 2003, Martin and Wilsey 2006); and (4) reducing soil erosion (Pimental et al. 1995).

Seed limitation has been shown to be a significant factor in early-successional communities (Turnbull et al. 2000), communities with ephemeral seed banks (Seabloom et al. 2003), wet grasslands (Xiong et al. 2003) and temperate grasslands (Wilsey and Polley 2003). It is important to understand plant recruitment through seed introduction because it directly affects the composition and diversity of 
the plant community (Turnbull et al. 2000, Nathan and Muller-Landau 2000, Howe and Brown 2001, Pywell et al. 2002, Foster and Tilman 2003, Xiong et al. 2003). A question is whether granivory and seedling herbivory by small mammals are likely to affect the success of restoration through seed addition in wet grasslands.

The present study directly addresses the question of bird and small mammal impact, particularly meadow voles, on a wet meadow restoration. We use an exclosure and seed addition experiment in Ohio to explore the effects of herbivorous meadow voles Microtus pennsylvanicus on plant community biomass, richness and diversity. We ask whether ambient populations of these small mammals: (1) alter species composition (e.g. forb/grass/sedge, proportion of invasives, proportion of non-natives); (2) influence plant diversity; and (3) reduce the affect of increasing local plant richness through seed introductions. The role of herbivores, particularly granivores, has been shown to be important in seedling establishment (Brown and Heske 1990, Hulme 1998, Nathan and Muller-Landau 2000, Howe and Brown 2000, 2001, Orrock et al. 2006). By the experimental control of seed predation and seed introduction we can better understand the mechanisms that determine species richness at the local scale and the effect of meadow voles on wet meadow vegetation.

\section{Material and methods}

\section{Study site}

The study was conducted at the 163.5 ha Bath Nature Preserve (BNP; $\left.41^{\circ} 10^{\prime} 36.2^{\prime \prime} \mathrm{N}, 81^{\circ} 38^{\prime} 58.7^{\prime \prime} \mathrm{W}\right)$, Bath Township, Summit County, OH, USA, in a 6-ha section of an old-field, wet meadow. Historically, the site was likely a mixed marsh and scrub wetland, but was converted into a field for growing hay approximately fifty years ago. The drainage tiles installed are no longer fully functional. The site is now a wet meadow due to the presence of standing water in the spring, wetland vegetation and hydric soils. Hydrological data showed that the water level was at a high of $25 \mathrm{~cm}$ aboveground in February 2003 with a gradual drawdown to $75 \mathrm{~cm}$ belowground in August 2003 (Feinstein pers. comm.).

Until 1996, the study site was harvested one to three times per year. From 1997 through the present, the area has been mown annually in September, near or at the end of the growing season, and the mown vegetation has been left on the field. The dominant vegetation is an herbaceous, graminoid community largely dominated by non-native European grasses including Phalaris arundinacea, Poa pratensis, Festuca arundinaceae and Agrostis stolonifera.

The meadow vole Microtus pennsylvanicus population was monitored from July 2002 to July 2004 using a 50-trap $90 \times 40 \mathrm{~m}$ trapping grid and estimated to fluctuate between a low of 51 in April 2004 to a high of 422 in July 2003 (Madson 2004).

The site was surveyed on a monthly basis during the growing season of 2002 to compile a total plant species list (Madson 2004). In addition, the seed bank was tested in April 2002 (Madson 2004). A $10 \mathrm{~cm}^{3}$ soil core was collected from the outside corner of each of the six blocks used in the seed addition experiment (see experimental design below) for a total of 24 samples. The soil from each core was evenly distributed overtop a $3 \mathrm{~cm}$ layer of sand in separate plant trays, watered daily with distilled water and grown in the greenhouse. A daily 14-h photoperiod (as recommended by Baskin and Baskin 1998) was provided by four $1000 \mathrm{~W}$, high pressure sodium bulbs. The germinated plants were identified on a weekly basis, and counted over a six month period. If a plant could not be identified it was transplanted to a separate 1-1 pot, labeled, and cultivated until identification was possible. Not all the carices were identifiable to species.

Species were separated by: (1) life form (grass, forb, sedge), (2) nativity (native or non-native, and (3) weedy invasiveness (invasive or non-invasive. These categories were extracted from the USDA Plants Database <http:// plants.usda.gov/index.html $>$. The life form category was chosen because it has been investigated in other vole palatability studies (Howe et al. 2002). Nativity and weedy invasiveness were selected because of their effect on restoration success.

\section{Experimental design}

To test our questions a $2 \times 2$ factorial design was used. The factors included a seed addition treatment $(0$ and 20 seed species added) and an exclosure treatment (open and fenced to exclude all mammalian and bird herbivores and granivores). A five and ten seed species mixture was also added, but only without exclosures. Since these data were superfluous they are not presented here (Madson 2004).

Twenty species of seeds were selected to represent a broad range of plant life forms typically found in temperate eastern North American wet meadow communities (Crow and Hellquist 2000) (Table 1). All species were obligate or facultative wetland species with forbs, grasses and sedges represented. The seed source was a combination of fieldcollected and cultivated plants that were bulk-processed to maximize genetic variability.

Three species needed treatment in order to break seed dormancy. Carex vulpinoidea and Scirpus cyperinus were cold stratified for sixty days, placed in a plastic bag with moistened sand and refrigerated at $4^{\circ} \mathrm{C}$ (Baskin and Baskin 1998). Allium cernuum was scarified in concentrated sulfuric acid $\left(\mathrm{H}_{2} \mathrm{SO}_{4}\right)$ for $25 \mathrm{~min}$ (Baskin and Baskin 1998). After scarification the seeds were washed with distilled water for $30 \mathrm{~s}$.

Seeds were sown in March 2003. The total number of seeds for the seed addition treatment was held constant at 3000 seeds: 150 seeds species ${ }^{-1} \times 20$ species. The seeds were sown in plots of $1 \mathrm{~m}^{2}$, with $2 \mathrm{~m}$ between plots. Four plots made up one block, which was replicated six times for a total of 24 plots. Each block measured $7 \times 4 \mathrm{~m}$. Within the blocks the treatment plots were randomized. The exclosures were $1.2 \mathrm{~m} \varnothing$ circles with a height of $1.2 \mathrm{~m}$ constructed from $1.27 \mathrm{~cm}$ galvanized hardware wire mesh. Wire mesh covers were placed over the top to prevent birds from entering. A girdle of wire mesh was dug $0.6 \mathrm{~m}$ into the ground to prevent burrowing animals from entering. 
Table 1 . The twenty plant species that were added as seed to experimental plots. Numbers represent the no. of plots where plants were found in final harvest (max. no. is 6). No number means there were zero individuals of the listed species. Open are plots without exclosures, and Exl are plots with exclosures. ${ }^{*}$ indicates the species naturally occurring on site (Madson 2004).

\begin{tabular}{|c|c|c|c|c|}
\hline \multirow[t]{3}{*}{ Species } & \multicolumn{4}{|c|}{ No. of seeds added } \\
\hline & \multicolumn{2}{|l|}{0} & \multicolumn{2}{|c|}{20} \\
\hline & Open & Exl & Open & Exl \\
\hline \multicolumn{5}{|l|}{$\begin{array}{l}\text { Allium cernuum } \\
\text { Andropogon gerardii }\end{array}$} \\
\hline $\begin{array}{l}\text { Bromus altissimus } \\
\text { Carex vulpinoidea } \\
\text { Desmanthus illinoiensis } \\
\text { Echinacea purpureum }\end{array}$ & & & 1 & $\begin{array}{l}2 \\
6\end{array}$ \\
\hline *Eleocharis palustris & & & 3 & 1 \\
\hline Elymus virginicus & & & 1 & 6 \\
\hline Glyceria Canadensis & & & 2 & 2 \\
\hline Glyceria occidentalis & & & & 1 \\
\hline *uncus effuses & & 2 & & \\
\hline $\begin{array}{l}\text { Juncus tenuis } \\
\text { Juncus torreyi }\end{array}$ & 1 & & 2 & 1 \\
\hline Liatris spicata & & & 1 & \\
\hline Rudbeckia hirta & & & & \\
\hline Rumex orbiculatus & & & 2 & 6 \\
\hline Scirpus cyperinus & & & & 1 \\
\hline Scirpus expanses & & & & \\
\hline Sparganium americanum & & & & \\
\hline Spiraea alba & & & & \\
\hline Total & 1 & 2 & 12 & 24 \\
\hline
\end{tabular}

Above-ground biomass of the vegetation was harvested in August 2004 of the second growing season. To avoid edge effects the central $0.25 \mathrm{~m}^{2}$ was harvested. The harvested material was taken back to the lab, sorted to species, oven-dried and weighed.

\section{Statistical methods}

A general linear model (GLM) was used to measure for block effect on biomass, species richness and diversity, with the seed addition treatment and exclosure treatments as factors. No block effect was found, allowing us to treat our replicates as independent samples.

Results were separated into three sections. (1) A threeway ANOVA was used to test treatment effects of seed addition and exclosure plus the categorical distinction of plant form (grass, forb, sedge) on the above-ground dry biomass and species richness. (2) A two-way ANOVA was done to test the treatment effects of seed addition and exclosure on (a) the proportion of biomass of weedy invasive species compared to total biomass and (b) the proportion of biomass of non-native species compared to total biomass. (3) Finally, a two-way ANOVA was used to determine treatment effects of seed addition ( 0 and 20 seeds) and exclosure (open and exclosure) on the aboveground dry biomass plus litter, species richness, and diversity (measured as the Shannon-Weiner index). Tukey's HSD was used to separate treatment means. All data were tested for normality and homogeneity of variances. All statistical analyses were performed using SPSS Systat 8.0.

\section{Results}

Eleven of the twenty species added established within the plots (Table 1); however, two of those species (Eleocharis palustris and Juncus effuses) occurred naturally on-site (Madson 2004). It is possible that these two species were not introduced by the experimental seed addition but from natural seed dispersal. This appears likely for $J$. effuses, which occurred in plots that received no experimental seed addition (Table 1), unless $J$. effuses seed that was experimentally added dispersed from its intended treatment plot. Carex vulpinoidea, Elymus virginicus and Rumex orbiculatus were found in six of the 20 seed addition exclosure plots available (Table 1).

\section{Three-way ANOVAs for plant form, exclosure and seeding on biomass and species richness}

Plant form (11 grass species, 11 forb species and 10 sedge species) showed a significant difference in biomass $\left(\mathrm{F}_{2,60}=\right.$ 67.358, $\mathrm{p}<0.001)$. Overall, grass species had the greatest biomass and forbs the least. There were no direct treatment effects (exclosures and seeding) on biomass, plus there was no interaction effect between plant form and the two experimental treatments.

Species richness was also affected by plant form $\left(\mathrm{F}_{2,60}=\right.$ 21.411, $\mathrm{p}<0.001$ ), with grass species having the highest numbers of species and forbs the lowest (Fig. 1). There was a significant interaction effect between plant form and exclosure on species richness $\left(\mathrm{F}_{2,60}=6.131, \mathrm{p}=0.004\right)$. Forbs showed a significant increase in species numbers within the exclosure treatments compared to the open treatments (Fig. 1).

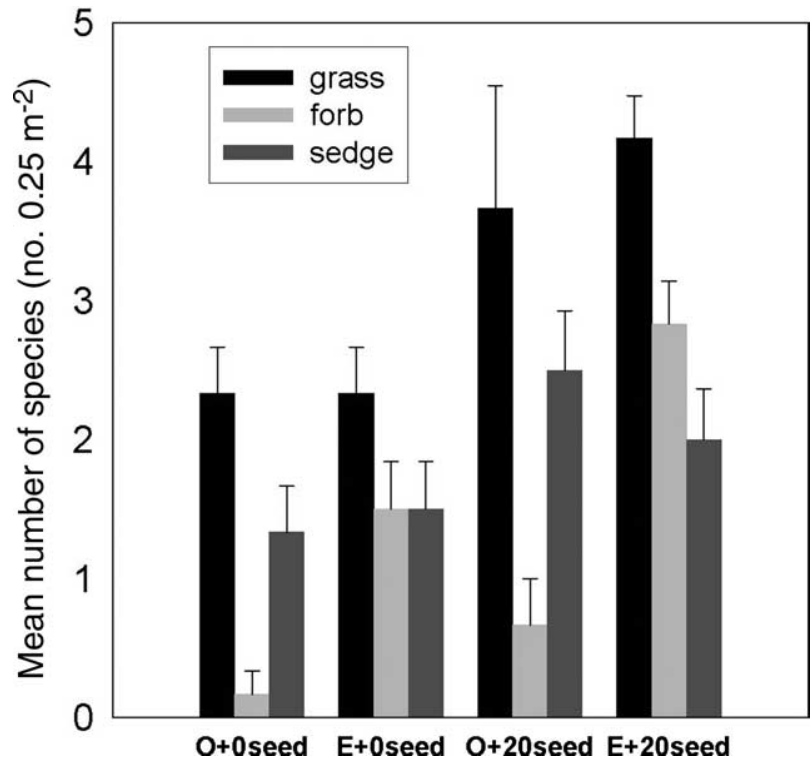

Figure 1. Effect of seed addition (0 and 20 seeds) and exclosure $(\mathrm{O}=$ open and $\mathrm{E}=$ exclosure) with respect to plant form (grass, forb, sedge) on mean species richness. Error bars represent $\mathrm{SE}+1$. 
Two-way ANOVAs for exclosure and seeding on proportion of invasive and non-native biomass

The proportion of 'invasive' species biomass was significantly decreased by exclosure $\left(\mathrm{F}_{1,20}=6.691, \mathrm{p}=0.018\right)$ and by seeding $\left(\mathrm{F}_{1,20}=10.202, \mathrm{p}=0.005\right)$ (Fig. 2). The interaction effect was not significant. Tukey's test showed that the lowest proportion of invasive species occurred in the seed added, herbivore exclosure plots (Fig. 2). The proportion of 'non-native' species biomass was not affected by seeding, exclosures or the interaction of the two factors.

\section{Two-way ANOVAs for exclosure and seeding on primary productivity, species richness and Shannon diversity}

Primary productivity, as measured by aboveground biomass plus litter within a $0.25 \mathrm{~m}^{2}$ area, was significantly affected by the exclosure treatment $\left(\mathrm{F}_{1,20}=4.762, \mathrm{p}=0.041\right)$, with the highest productivity found in the exclosure plots (Fig. 3a). Seed addition did not affect productivity. The interaction effect was not significant. Tukey's test showed that the highest productivity occurred in the seed added, herbivore exclosure plots (Fig. 3a).

Species richness per $0.25 \mathrm{~m}^{2}$ was significantly higher within the exclosure treatments $\left(\mathrm{F}_{1,20}=4.682, \mathrm{p}=0.043\right)$ (Fig. 3b). Furthermore, seed addition increased species richness $\left(\mathrm{F}_{1,20}=17.845, \mathrm{p}<0.001\right)$ (Fig. $\left.3 \mathrm{~b}\right)$. However, the interaction effect was not significant. Tukey's test showed that the highest species richness occurred in the seed added, herbivore exclosure plots (Fig. 3b).

Exclosures caused a significant increase in Shannon diversity $\left(\mathrm{F}_{1,20}=7.672, \mathrm{p}=0.012\right)$, but seeding did not (Fig. 3c). Once again, the interaction effect was not

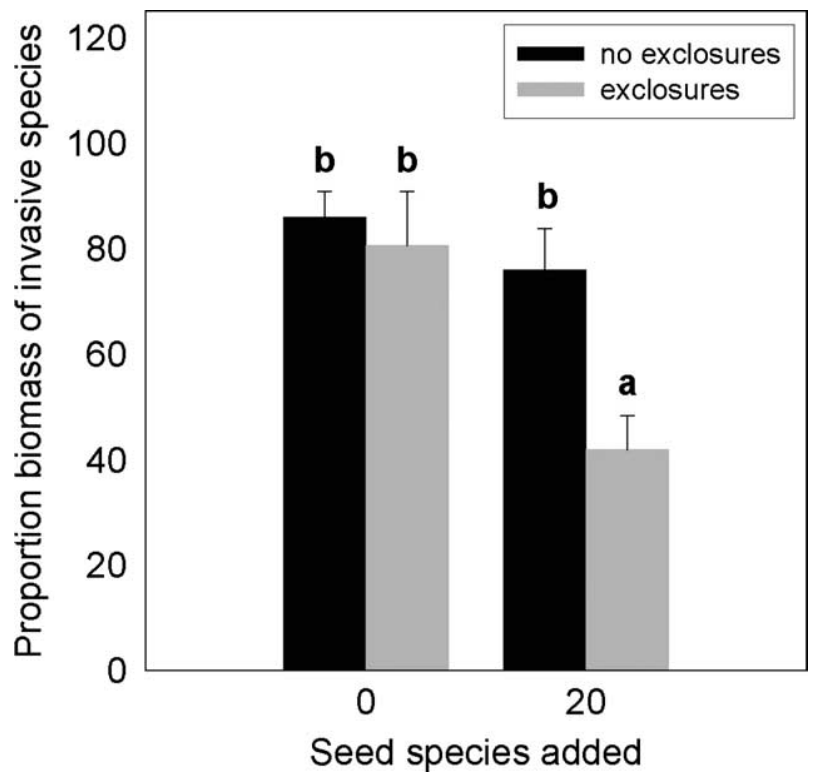

Figure 2. Effect of seed addition ( 0 and 20 seeds) and exclosure $(\mathrm{O}=$ open and $\mathrm{E}=$ exclosure $)$ on the proportion of total biomass represented by invasive species (Table 1). Error bars represent SE +1 .
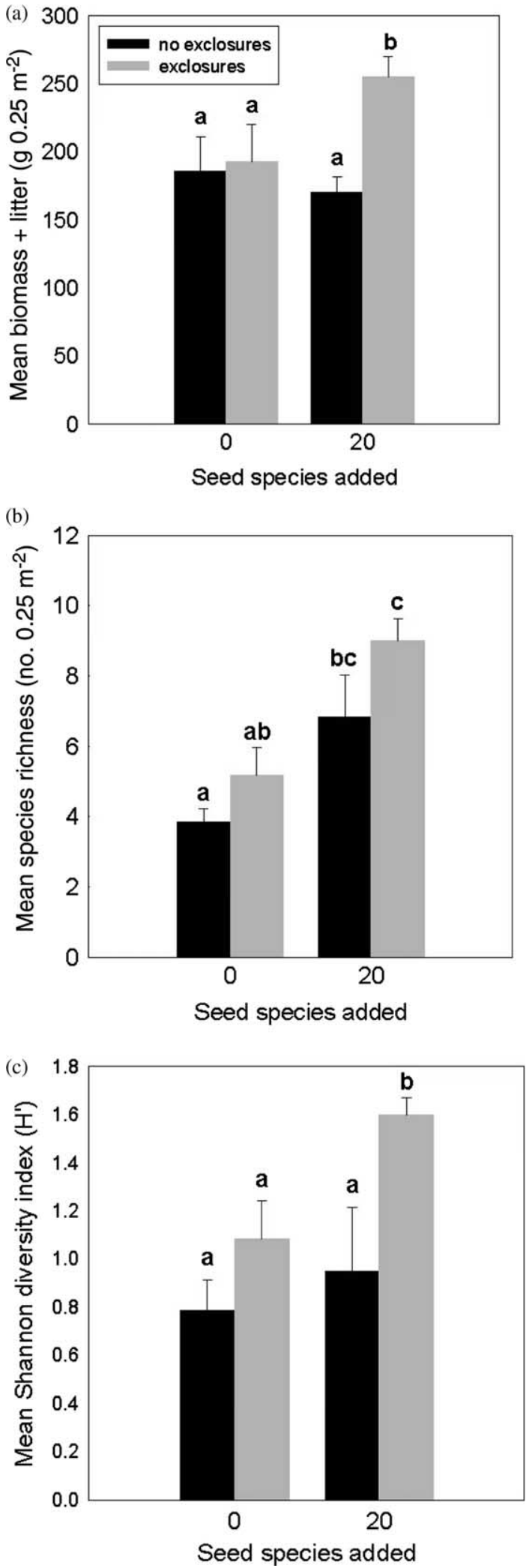

Figure 3. Effect of seed addition ( 0 and 20 seeds) and exclosure (open $=$ dark bars and exclosure $=$ light bars) on: (a) mean biomass + litter; (b) mean species richness; and, (c) mean Shannon diversity. Error bars represent SE +1 . Bars sharing the same letter are not significantly different $(\mathrm{p}<0.05)$ using Tukey's test. 
significant. Tukey's test determined that diversity was highest in the seed added, herbivore exclosure plots (Fig. 3c).

\section{Discussion}

Seed addition is a common approach in restoration projects, but propagule success is often dependent on site characteristics (Burke and Grime 1996, Turnbull et al. 2000, Foster and Dickson 2004, Martin and Wilsey 2006). The goal of our study was to determine if small mammals and birds, through herbivory and granivory, affect the relative success of re-colonizing native species in a wet meadow dominated by non-native European grasses. While our results suggest that seed addition can increase species richness in established wet grassland, so too does the exclusion of herbivores and granivores.

In answer to our first question, species composition was affected by our experimental manipulations. Forb species biomass was significantly greater inside exclosures relative to their paired open treatment. In another experiment, Howe et al. (2002) found that vole herbivory increased forbs, but the two forbs in question were unpalatable species (Echinacea purpurea and Rudbeckia hirta). We also sowed these two forb species but they failed to colonize inside our study plots. The forb that was introduced through seed addition, and increased in the exclosures, was Rumex orbiculatus, which was likely palatable to voles. Plant species that are palatable to voles are removed from or reduced in the community (Howe et al. 2002, 2006, Howe and Lane 2004). Therefore, any changes in broad plant form functional groupings (in this case grass, forb, and sedge) are probably not attributable to the particular plant form but rather to specific species palatability.

Another component of plant composition that was affected by our experimental treatments was the proportional biomass of invasive species. Here we found that the relative biomass of invasives within the 20 species seed addition plus exclosure treatment was approximately half of the other treatment combinations. Therefore both seed addition and small mammal/bird exclosures are necessary to reduce the proportion of invasive plants in the community. Theoretical and empirical research suggests that increased species diversity reduces the susceptibility of a plant community to invasion (Naeem et al. 2000, Carpinelli et al. 2004). We suggest that by increasing diversity with niche-differentiated native species the intrinsic result was a community resistance to invasive plant species.

To address our second question, we found that exclosures significantly affected species richness and diversity, with more plant species found within exclosures compared to the open plots. While this result may seem contrary to other exclosure experiments that demonstrated fewer species when herbivores were removed (Crawley 1983, Olff and Ritchie 1998), these other experiments did not generally exclude small mammals, nor did they involve the combination of seed introduction. Grazing by large vertebrates can increase plant diversity by reducing the biomass of dominants, thereby releasing competitive suppression - referred to as the hump-backed model of plant species richness (Grime 1973, 1979). Small mammals can also reduce plant biomass (Howe et al. 2006), but not likely at the same high rate as large grazers.

Similar to our findings, an exclosure experiment in Illinois showed a decline in herbaceous plant diversity in the presence of voles (Howe et al. 2002). We should also point out that while we detected an increase in species richness and diversity within the exclosures, the increase was largely driven by the emergence and establishment of experimentally sown seeds. It is questionable how long these juvenile plants might remain within the community, even if the herbivore exclosures were maintained, given the potential ongoing effects of competition.

Finally, our third question was to address whether small mammals reduce the effect of increasing local plant richness through seed introductions. Few studies have investigated restoration through seed addition in combination with granivory and seedling herbivory (Nelson et al. 1970, Howe and Brown 1999, 2000, MacDougall and Wilson 2007). This is surprising considering that any seed addition experiment should also account for seed and seedling predation (Archer and Pyke 1991, Hulme 1998, MacDougall and Wilson 2007). Often, alternative factors such as climate, competition, or poor germination have been cited to explain lack of establishment following seed introduction (Sullivan and Sullivan 1984, Archer and Pyke 1991, Bakker et al. 2003, Zeiter et al. 2006). Our experimental study was designed to separate vole and bird granivory as a causal factor limiting seed propagation.

Meadow voles are herbivores that preferentially feed on seedlings and young plant tissue (Huntly 1991); therefore, they can have a strong effect on emerging grassland assemblages (Howe and Brown 1999). Seed addition plots had higher plant richness, providing support for the seed limitation hypothesis. However, nine of the 20 species that were experimentally sown were not found in the plots, suggesting that there are constraints on seedling germination and establishment within the established canopy of the wet meadow at the Bath Nature Preserve. Although granivory and herbivory would seem to play an important role in plant community structure, competition and other factors are also likely to be important as these emerging seedlings attempt to colonize under an established canopy.

Our results support the seed limitation hypothesis, which suggests that the number of plant species found at the local scale is limited by seed propagules (Ericksson 1993, Seabloom et al. 2003, Martin and Wilsey 2006). Zobel et al. (2000) also found that areas are more likely to be species poor when the number of species in the seed rain is correspondingly low. However, seed introduction, germination and establishment are complex issues involving strong biotic and abiotic factors. Crawley (1990) reviewed several studies where there was no recruitment from seed additions. Old fields that were not mown showed very little seedling emergence. This was consistent with another review of 27 seed addition studies, where Turnbull et al. (2000) concluded that seed addition is less likely to have an effect on the plant community composition of vegetation in later successional stages.

Once germinated, competition certainly played a role. Growth of the seedlings was undoubtedly suppressed by 
other plants for resources such as light and nutrients (Keddy et al. 1998, Freckleton and Watkinson 2001, Foster and Dickson 2004, MacDougall and Turkington 2004, Carlyle and Fraser 2006). Our experiment was not designed to test for competitive interactions; but the success of seed germination, seedling establishment and subsequent increase in plant diversity as a result of seed addition demonstrates that competition should not necessarily be overemphasized when considering plant community dynamics (MacDougall and Wilson 2007). Competition is not the only factor controlling species introduction in the wet meadow, granivory by voles and birds is another important factor affecting plant community composition and diversity.

There are many factors affecting the success of restoration and diversification by seed introduction. While our results show some support for the seed limitation hypotheses, it is also evident that seed and seedling predation are important factors that can control wet meadow community composition. Ultimately, restoration should increase native biodiversity, and therefore a restoration plan should include the number of native plant species that should be added and preventative measures to reduce granivory. To fully understand these processes, especially in our attempt to develop effective restoration goals, future studies should include: (1) controlled greenhouse studies to determine germination requirements of different species; (2) asymmetric competition experiments in the field between seedlings and mature plants; and, (3) a better understanding of the feeding preferences of granivores and herbivores. Successful restoration that results in higher plant diversity has the added benefit of potentially reducing invasion by non-native and weedy plant invasives.

Acknowledgements - We thank Steve Damm, Sarah Edmonds, Chris Marks, Julie Nieset, Connie Hausman and Christa Schafer for field assistance. Katharine Suding helped to improve the manuscript. Peter Niewiarowski made useful comments on an earlier draft. This work was supported by a National Science Foundation GK-12 grant and a Canada Research Chair awarded to L. Fraser.

\section{References}

Archer, S. and Pyke, D. A. 1991. Plant-animal interactions affecting plant establishment and persistence on revegetated rangeland. - J. Range Manage. 44: 558-565.

Bakker, J. D. et al. 2003. Contingency of grassland restoration on year, site, and competition from introduced grasses. - Ecol. Appl. 13: 137-153.

Batzli, G. O. and Pitelka, F. A. 1970. Influence of meadow mouse populations on California grassland. - Ecology 51: 10271039.

Baskin, C. C. and Baskin, J. M. 1998. Seeds: ecology, biogeology and evolution of dormancy and germination. - Academic Press.

Brown, J. H. and Heske, E. J. 1990. Control of a desert-grassland transition by a keystone rodent guild. - Science 250: 17051707.

Burke, M. J. W. and Grime, J. P. 1996. An experimental study of plant community invasibility. - Ecology 77: 776-791.

Carlyle, C. N. and Fraser, L. H. 2006. A test of three juvenile competitive response strategies. - J. Veg. Sci. 17: 11-18.
Carpinelli, M. F. et al. 2004. Revegetating weed-infested rangeland with niche-differentiated desirable species. - J. Range Manage. 57: 97-105.

Crawley, M. J. 1983. Herbivory. The dynamics of animal-plant interactions. - Blackwell.

Crawley, M. J. 1990. Rabbit grazing, plant competition and seedling recruitment in acid grassland. - J. Appl. Ecol. 27: 803-820.

Crow, G. E. and Hellquist, C. B. 2000. Aquatic and wetland plants of northeastern North America, a revised and enlarged edition of Norman C. Fassett's A manual of aquatic plants. Vol. 1 and 2. - Univ. of Wisconsin Press.

Edwards, G. R. and Crawley, M. J. 1999. Rodent seed predation and seedling recruitment in mesic grassland. - Oecologia 118: 288-296.

Ericksson, O. 1993. The species-pool hypothesis and plant community diversity. - Oikos 68: 371-374.

Freckleton, R. P. and Watkinson, A. R. 2001. Asymmetric competition between plant species. - Funct. Ecol. 15: 615623.

Foster, B. L. and Tilman, D. 2003. Seed limitation and the regulation of community structure in Oak Savanna grassland. - J. Ecol. 91: 999-1007.

Foster, B. L. and Dickson, T. 2004. Grassland diversity and productivity: the interplay of resource availability and propagule pools. - Ecology 85: 1541-1547.

Grime, J. P. 1973. Control of species density in herbaceous vegetation. - J. Environ. Manage. 1: 151-167.

Grime, J. P. 1979. Plant strategies and vegetation processes. - Wiley.

Grime, J. P. 2001. Plant strategies, vegetation processes and ecosystem properties (2nd ed.). - Wiley.

Howe, H. F. and Brown, J. S. 1999. Effects of birds and rodents on synthetic tallgrass communities. - Ecology 80: 1776-1781.

Howe, H. F. and Brown, J. S. 2000. Early consequences of rodent granivory on synthetic dicot communities. - Ecol. Appl. 10: 917-924.

Howe, H. F. and Brown, J. S. 2001. The ghost of granivory past. - Ecol. Lett. 4: 371-378.

Howe, H. F. and Lane, D. 2004. Vole-driven succession in experimental wet-prairie restorations. - Ecol. Appl. 14: 12951305.

Howe, H. F. et al. 2002. A rodent plague on tallgrass diversity. - Ecol. Lett. 5: 30-36.

Howe, H. F. et al. 2006. Massive and distinctive effects of meadow voles on grassland vegetation. - Ecology 87: 3007-3013.

Huitu, O. et al. 2003. Winter food supply limits growth of northern vole populations in the absence of predation. - Ecology 84: 2108-2118.

Hulme, P. E. 1996. Natural regeneration of yew (Taxus baccata L.): microsite, seed or herbivore limitation? - J. Ecol. 84: 853861.

Hulme, P. E. 1998. Post-dispersal seed predation: consequences for plant demography and evolution. - Persp. Plant Ecol. Evol. Syst. 1: 32-46.

Huntly, N. 1991. Herbivores and the dynamics of communities and ecosystems. - Annu. Rev. Ecol. Syst. 22: 477-503.

Keddy, P. et al. 1998. A comparative approach to investigate competitive response of 48 wetland plant species. - J. Veg. Sci. 9: 777-786.

Keesing, F. 2000. Cryptic consumers and the ecology of an African savanna. - Bioscience 50: 205-215.

Knapp, A. K. et al. 1999. The keystone role of bison in North American tallgrass prairie. - Bioscience 49: 39-50.

Krebs, C. J. et al. 2002. Synchrony in lemming and vole populations in the Canadian arctic. - Can. J. Zool. 80: 1323-1333. 
MacDougall, A. S. and Turkington, R. 2004. Relative importance of suppression-based and tolerance-based competition in an invaded oak savanna. - J. Ecol. 92: 422-434.

MacDougall, A. S. and Wilson, S. D. 2007. Herbivory limits recruitment in an old-field seed addition experiment. - Ecology 88: 1105-1111.

Madson, E. B. 2004. Effects of herbivory and granivory on the seed bank in a wet meadow. - MSc thesis. - Univ. of Akron.

Martin, L. M. and Wilsey, B. J. 2006. Assessing grassland restoration success: relative roles of seed additions and native ungulate activities. - J. Appl. Ecol. 43: 1098-1109.

McNaughton, S. J. et al. 1991. Primary and secondary production in terrestrial ecosystems. - In: Cole, J. et al. (eds), Comparative analyses of ecosystems. Springer, pp. 120-139.

Milchunas, D. G. and Laurenroth, W. K. 1993. Quantitative effects of grazing on vegetation and soils over a global range of environments. - Ecol. Monogr. 63: 327-366.

Naeem, S. et al. 2000. Plant diversity increases resistance to invasion in the absence of covarying extrinsic factors. - Oikos 91: 97-108.

Nathan, R. and Muller-Landau, H. C. 2000. Spatial patterns of seed dispersal, their determinants and consequences for recruitment. - Trends Ecol. Evol. 15: 278-285.

Nelson, J. R. et al. 1970. Factors influencing broadcast seeding in bunchgrass range. - J. Range Manage. 23: 163-170.

Noss, R. F. and Cooperrider, A. Y. 1994. Saving nature's legacy: protecting and restoring biodiversity. - Island Press.

Noss, R. F. et al. 1995. Endangered ecosystems of the United States: a preliminary assessment of loss and degradation. Biol. Rep. 28. USDI Natl Biol. Service, Washington, DC.

Olff, H. and Ritchie, M. E. 1998. Effects of herbivores on grassland plant diversity. - Trends Ecol. Evol. 13: 261-265.

Oli, M. K. 2003. Population cycles of small rodents are caused by specialist predators: or are they? - Trends Ecol. Evol. 18: 105107.
Orrock, J. L. et al. 2006. Seed predation, not seed dispersal, explains the landscape-level abundance of an early-successional plant. - J. Ecol. 94: 838-845.

Pimental, D. et al. 1995. Environmental and economic costs of soil erosion and conservation benefits. - Science 267: 11171123.

Pywell, R. F. et al. 2002. Restoration of species-rich grassland on arable land: assessing the limiting processes using a multi-site experiment. - J. Appl. Ecol. 39: 294-309.

Seabloom, E. W. et al. 2003. Competition, seed limitation, disturbance, and reestablishment of California native annual forbs. - Ecol. Appl. 13: 575-592.

Sheley, R. L. and Half, M. L. 2006. Enhancing native forb establishment and persistence using a rich seed mixture. - Restor. Ecol. 14: 627-635.

Sullivan, T. P. and Sullivan, D. S. 1984. Influence of range seeding on rodent populations in the interior of British Columbia. - J. Range Manage. 37: 163-165.

Turnbull, L. A. et al. 2000. Are plant populations seed-limited? A review of seed sowing experiments. - Oikos 88: 225238.

Wilsey, B. J. and Polley, H. W. 2003. Effects of seed additions and grazing history on diversity and productivity of subhumid grasslands. - Ecology 84: 920-931.

Xiong, S. et al. 2003. Interactive effects of soil moisture, vegetation canopy, plant litter and seed addition on plant diversity in a wetland community. - J. Ecol. 91: 976-986.

Zeiter, M. et al. 2006. Recruitment limitation constrains local species richness and productivity in dry grassland. - Ecology 87: 942-951.

Zobel, M. et al. 2000. Is small-scale species richness limited by seed availability or microsite availability? - Ecology 81: 32743282 . 